\title{
FILOLOGÍA HISPÁNICA
}





\title{
«ARTÍCULO + POSESIVO + NOMBRE» FRENTE A «POSESIVO + NOMBRE» COMO VARIANTE INVISIBLE EN UN TEXTO MEDIEVAL
}

\author{
Ana Serradilla Castaño \\ Universidad Autónoma de Madrid \\ ana.serradilla@uam.es
}

\section{RESUMEN}

Este artículo parte de la hipótesis de que la estructura «artículo + posesivo + nombre» funciona en algunos textos medievales como una variante invisible. Se analiza, así, este concepto (Barra Jover, 2009), que alude a la alternancia de formas para una misma función por parte de un mismo hablante, que utiliza una u otra de manera inconsciente $\mathrm{y} \sin$ que medie un contexto determinado. A continuación, se analizan en una obra concreta, Calila e Dimna, los diferentes parámetros que pudieran resultar determinantes a la hora de seleccionar la construcción con o sin artículo (distancia con el referente, naturaleza del poseedor, tipo de nombre, función del sintagma en que aparece...) y se observa que ninguno de estos factores parece ser decisivo; no habría, por tanto, en la obra analizada ninguna motivación semántica, sintáctica o pragmática para la utilización de esta construcción, por lo que es posible aventurar que la hipótesis propuesta se confirma.

Palabras Clave: Variante invisible, variante motivada, artículo + posesivo + nombre.

\footnotetext{
${ }^{1}$ Este trabajo ha sido llevado a cabo en el marco de los Proyectos de Investigación (FFI2009-10817) y (FFI2009-12191), financiados por el Ministerio de Educación, y dirigidos por Inés Fernández Ordóñez y por Elena de Miguel respectivamente. Agradezco a Javier Elvira y Mario Barra la lectura de este estudio y sus sugerencias siempre interesantes.
} 


\section{ABSTRACT}

This paper departs from the hypothesis of the construction «determiner + possessive + noun» being an invisible variant in some medieval texts. The concept of invisible variant (Barra Jover 2009), which refers to the unconscious alternation of several forms for the same function in a given speaker and with no particular context involved, is first explored. The various parameters which might be relevant for choosing the construction with or without a determiner are then analyzed in Calila e Dimna. None of these parameters (distance to the referent, nature of the possessor, noun type, function of the phrase in which the pattern occurs...) prove decisive. Therefore, there is no semantic, syntactic or pragmatic motivation for the use of this construction in the text, so the initial hypothesis seems to be confirmed.

KEY WORDS: Invisible variant, motivated variant, determiner + possessive + noun.

\section{PUNTO DE PARTIDA}

El objetivo de este artículo es analizar en qué circunstancias puede aparecer la construcción «artículo + posesivo + nombre» en una obra medieval concreta o, dicho de otra forma, qué condiciones, si es que estas existen, tienen que darse para que un autor, escriba o traductor (hablante, al fin y al cabo) opte por utilizar esta secuencia y no otra en su discurso en un momento dado.

Puesto que en los textos en verso las necesidades métricas pueden condicionar en gran medida la elección de la construcción con o sin artículo, he considerado más relevante para la obtención de resultados fiables recurrir a textos en prosa y por eso centraré mi análisis, en principio, aunque es necesario, obviamente, realizar comparaciones con otros textos de la época, en Calila e Dimna, obra de una determinada tradición discursiva (Kabatek, 2008), perteneciente a una época en la que eran posibles tanto la estructura con artículo y posesivo como la estructura solo con posesivo.

Company (2006: 67), al analizar estas construcciones, plantea una serie de reflexiones y se hace una pregunta a la que también me sumo:

El estudio de las frases del tipo el mi amigo, la su casa, más allá de su propio interés descriptivo para un mejor conocimiento del español medieval, es importante porque atiende a la pregunta fundamental de la variación lingüística y el cambio lingüístico, formulada explícitamente hace casi tres décadas por Bolinger, a saber: «¿en determinado contexto qué razón tendría un hablante para emplear una forma que es más ligera en contenido semántico que otra que es más plena, o viceversa?». Esto es, ¿qué motiva la elección de una forma lingüística vs. otra, ambas equivalentes desde un punto de vista semántico? En el caso de la construcción artículo + posesivo, la pregunta es la siguiente: ¿por qué mantener una estructura posesiva sobreespecificada en la gramática de una lengua, si otras construcciones posesivas pueden codificar una relación posesiva referencialmente similar? 
Mi hipótesis es que, aunque en determinadas situaciones en textos de épocas posteriores o de diferentes géneros pueda haber distintos factores (focalización, contraposición, influencia del texto origen en las traducciones, emotividad, expresividad...2 ${ }^{2}$ que propicien el uso de una u otra construcción ${ }^{3}$, en los pasajes analizados del Calila la elección podría surgir como una «variante invisible». Así, en el Calila, y también en otros textos medievales, los autores recurren en ocasiones a la estructura con artículo y en otros casos a la estructura solo con posesivo sin que aparentemente existan razones para la selección de una u otra forma.

Antes de continuar, es conveniente detenerse en la explicación de este concepto de variante invisible (Barra Jover, 2009a y 2009b), que alude a la alternancia de formas, consideradas gramaticales en una época, para una misma función por parte de un mismo hablante, que utiliza una $\mathrm{u}$ otra de manera inconsciente y sin que medien un contexto o un cotexto determinados.

Una variante invisible existe cuando un mismo locutor puede usar para la función A la variante $\mathrm{a}_{1}$ y la variante $\mathrm{a}_{2}$ sin tener consciencia de ello (sin dominar la alternancia) y sin que ello dependa de la situación. Quisiera insistir en que lo que interesa es que se trate del mismo locutor y que solo tiene interés observar la variante desde un punto de vista idiolectal y teniendo también en cuenta que el receptor tampoco es sensible a tales variantes. (Barra Jover, 2009b: 21)

Estamos ante un concepto que ha sido aplicado ya por este autor (Barra Jover, 2009a) en español antiguo a fenómenos como el leísmo o la presencia de subordinadas con o sin preposición, y en español moderno al uso de construcciones como lo volveré a hacer frente a volveré a hacerlo, entre otras. Se trataría de estructuras que un hablante puede alternar en su discurso sin ser consciente de ello, sin ninguna voluntad estilística y sin ninguna intención pragmática. Así, ante ejemplos como (1) podemos también pensar que, en principio, el uso de ambas construcciones alterna sin motivación aparente y sin que una de ellas aporte valores que no posea la otra:

(1) ca dizen que quien se trabaja deste siglo es la su vida contra sí, et el que se trabaja deste siglo et del otro es su vida a par de sí o contra sí. Et dizen que en tres cosas se deve el seglar emendar: en la su vida, et afiar la su ánima por ella; et la segunda es por la fazienda deste siglo et por la fazienda de su vida (p. 97).

Solo cuando la evolución lingüística provoque que una de las construcciones «desaparezca» o quede estigmatizada -en este caso la construcción con artículo-, esta variante se hará visible y su uso podrá, en las áreas en las que no remite completamente, aportar nuevos valores semánticos y pragmáticos (contraposición, unicidad, focaliza-

\footnotetext{
${ }^{2}$ Como muy bien señala Company (2006: 103): «en última instancia, el estilo no es sino la explotación, consciente o inconsciente, de los recursos gramaticales disponibles en una lengua».

${ }^{3}$ Sobre esta construcción, tanto en español antiguo como en la actualidad, he trabajado ya en anteriores ocasiones; véanse Serradilla (2003) y (2007). En estos estudios se analizan los diversos valores que la secuencia artículo + posesivo + nombre puede aportar en diferentes épocas. Se trata de un tema que ha merecido la atención de no demasiados investigadores, sin embargo, tal y como recoge Company (2009b: 104), en los últimos años ha aparecido una docena de artículos dedicados al estudio de la construcción artículo + posesivo + nombre, entre los que se incluyen los artículos que acabo de reseñar.
} 
ción...), que, por sí misma, la variante «triunfadora»-la secuencia solo con posesivo- no transmite. Véase, en este sentido, la evolución que propone Barra Jover (2009a: 111):

(11) Variante invisible $>$ variante visible partielle $>$ variante visible genérale $>$ disparition de l'une des posibilites.

(11") Variante invisible > variante visible partielle ou genérale > remotivation de la variante 4 .

En las páginas siguientes presentaré los datos de que dispongo con el fin de comprobar si estamos ante un caso de variante invisible o si es posible encontrar alguna causa que motive el uso de una u otra construcción.

\section{La CONSTRUCCión ARTÍ́CULO + POSESIVO + NOMBRE EN CALILA E DimNa}

Antes de nada, me gustaría hacer una brevísima reflexión en torno al tipo de obra analizada: estamos ante un texto del escritorio alfonsí, traducción de un texto árabe de mediados del siglo VIII, muy difundido gracias a las muchas traducciones que circularon durante toda la Edad Media y que, a su vez, tiene su origen en una recopilación de cuentos orientales persas. Esta colección de cuentos, protagonizados por animales, responde a un género muy extendido desde las épocas más antiguas; la estructura es relativamente, simple: se van recogiendo fábulas, que son introducidas por algún personaje, quien da pie a moralizaciones. El diálogo ocupa una gran parte del texto y, en principio, se intenta reflejar la oralidad ya que, de hecho, las historias referidas en la obra pertenecen a la tradición popular recogida oralmente durante siglos 5 .

Lingüísticamente, los textos traducidos tienen, en ocasiones, como es lógico, algunas interferencias de la lengua de origen. En el caso concreto que estoy analizando, la mayor presencia de artículo podría justificarse, precisamente, por el hecho de que el árabe utilice el artículo con más frecuencia que el español medieval; no obstante, tras una lectura pausada del texto se observa que, salvo en el caso de esta construcción, no se encuentran usos anómalos del artículo.

En todo caso y como era de esperar, la construcción más frecuente es aquella en la que no aparece el artículo y el posesivo es el único determinante del sustantivo. De hecho, en todo el texto solo he localizado 62 apariciones de la construcción con artículo, frente a varios cientos de la secuencia más simple. Esta frecuencia de aparición, que no deja de ser significativa, es, pues, claramente minoritaria; sin embargo, el que haya 62 ejemplos (junto a 13 de un/una su) nos obliga a tenerla en cuenta, en el sentido de que no es una construcción que aparezca únicamente de forma esporádica ${ }^{6}$. En la siguiente tabla

\footnotetext{
${ }^{4}$ En Barra Jover (2009b: 21) podemos leer la siguiente interpretación para la evolución lingüística: «[...] una evolución en una lengua puede ser representada como la situación en la que una variante invisible se hace visible, circunstancia que puede desencadenar un salto cualitativo en la gramática social si el conjunto de los locutores interioriza la diferencia».

${ }^{5}$ Según la información presentada por Alvar y Lucía (2002: 231) estamos ante una obra traducida en 1251, que nos ha llegado a través de 2 códices, A y B, conservados en El Escorial y copiados a finales de los siglos XIV y XV respectivamente. Asimismo, se conservan otros dos fragmentos también tardíos.

${ }^{6}$ No estamos, ni mucho menos, ante una construcción extraña; téngase en cuenta que el uso de artículo + posesivo ante nombre está presente en toda las lenguas romances y en todas ellas ha habido vacilaciones en el uso, lo que nos orienta a una situación protorromance o latinotardía.
} 
se recoge la distribución de las apariciones de la estructura con artículo + posesivo + nombre:

TABLA 1

\begin{tabular}{|ll|ll|lc|lc|}
\hline la mi: & 7 & el mi: & 7 & las mis: & 0 & los mis: & 1 \\
\hline la tu: & 8 & el tu: & 10 & las tus: & 2 & los tus: & 0 \\
\hline la su: & 13 & el su: & 8 & las sus: & 3 & los sus: & 1 \\
\hline la nuestra: & 1 & el nuestro: & 0 & las nuestras: 1 & los nuestros: 0 \\
\hline la vuestra: & 0 & el vuestro: & 0 & las vuestras: 0 & los vuestros: 0 \\
\hline
\end{tabular}

A continuación, se muestran algunos ejemplos del Calila en los que se documenta la alternancia de las construcciones con y sin artículo en un mismo párrafo:

(2) Et sepas que la primera cosa que conviene al que este libro leyere es que se quiera guiar por sus anteçesores, que son los filósofos et los sabios, et que lo lea, et que lo entienda bien, et que non sea su intento de leerlo fasta el cabo sin saber lo que ende leyere: ca aquel que la su intençión será de leerlo fasta en cabo et non lo entendiere nin obrare por él non fará pro el leer nin avrá dél cosa de que se pueda ayudar. (p. 91)

(3) Et tovo por cosa vergonçosa de tornar a su señor el rey con tan mal recabdo, et quexóse desto a los filósofos de los reyes de India. Et ellos dixéronle que eso mesmo fallaran ellos en sus escripturas que él avía fallado, et, propiamente, el entendimiento de los libros de la su filosofía et el saber que Dios puso en ellos son los cuerpos, et que la melezina que en ellos dezía son los buenos castigos. (pp. 100-101)

(4) Et desí pusiéronme con los maestros, et yo non çeçé de continuar en aprender la gramática et de meter la mi cara a sotileza et a buen entendimiento, atanto que vençí a mis conpañeros et a mis iguales, et valí más que ellos. (p. 103)

(5) Et leí libros, et conosçí et sope sus entendimientos, et afirmóse en el mi coraçón lo que leí de las escripturas de los filósofos. (p. 103)

(6) Et non avía enbidia de mis iguales, nin de los que avían más aver que yo, nin del bien que Dios les avía dado. Mas [era] el mio mayor cuidado, et a lo que yo más me enclinava et de lo que más me trabajava, que pugnase más qu' él en saber et en me trabajar en aver gualardón de Dios. (p. 105)

(7) ¡Ay alma!, non te engañes en la conpañía de tus amigos et de tus bien querientes, et non ayas desto grand cobdiçia, pues que a la fin la su conpañía se ha de partir. (p. 106) ${ }^{7}$

(8) Así yo temíme de ir acá et allá et después ser preso por mi culpa, et ove por bien de non me temer de aquello de que me temía. Et detove mi mano de ferir et de abiltar et de robar et de furtar et falsar. Et guardé el mi cuerpo de las mugeres, et mi lengua de mentir et de toda razón que daño fuese a alguno. (p. 112)

(9) Desí tórnalo tal commo la quajada espesa, et desí desparte et devisa sus mienbros a sus tienpos. Et si es macho, tiene la cara con[tra] el espinazo de su madre, et cúnplese la su forma et la su criazón en quarenta días; et si es muger, tiene la cara con[tra] el vientre de su madre, et cúnplese la su criazón. (p. 116)

\footnotetext{
${ }^{7}$ En la edición de Solalinde se lee la tu compañía.
} 
(10) Et yo, señor, non te di este enxenplo sinon porque he esperança que sea esta cosa, cuya boz te espantó, atal commo el atanbor; et si a ella te llegases, más lijera te semejaría que tú non cuidas. Et, señor, si fuere la tu merçed, enbíame a ella et está tú en tu lugar fasta que yo torne a ti con lo que sopiere de su fazienda. (p. 135)

(11) Et en esto cuidó el camello mezquino que, quando él dixiese commo dixieron los otros, que lo escusarían por que estorçiese commo ellos, et que sería pagado el león como se pagó de llos otros, et dixo: - En mí as fartura quanto quieras, ca mi carne es muy buena et alva et sana, et el mi vientre es muy linpio, et non ha en mí tacha ninguna. (p. 162)

(12) Dixo Digna: - ¿Por qué catas con un ojo et oyes con una oreja et non piensas en la cosa cómmo es, nin la sabes de çierto, mas fazes a tu sabor non sabiendo la verdat? Mas parésçeme que la mi mal andançia ha mudado a ti por razón de mí todas las cosas, et aun todos los otros, que ninguno non fabla nin razona sinon a su sabor. (p. 186)

(13) Dixo Digna: - Bien me as aconsejado, et dizes verdat: enpero veré a qué tornará la mi çima de mi fazienda et qué mandarán de mí fazer. (p. 190)

(14) Et non deve el omne entendido alegrarse por grand aver, nin aver pesar por lo poco: mas el su aver con que se deve alegrar es su entendimiento. (p. 219)

(15) [ha] en su fuerça sobre los flacos, et se engañan por esto los fuertes, su fuerça es cobardez et mala andançia contra sí: porque sabedes quánta mejoría ha la fuerça que avedes sobre las otras bestias, fuestes atrevidos contra mí, et benistes a la fuente que le dizen el mi nonbre et tomastes mi agua et bevístesla vós et vuestras conpañas. (p. 232)

(16) Dixo el galápago: - Non se me tovo de te venir ver, con quanto deseo he de ti, sinon por vergüença de ti, que tan poco te gualardoné el bien que me feziste: ca, maguer que yo sé que tú non quieres gualardón del bien que me feziste, téngome por adebdado de te lo gualardonar: ca la tu costunbre es de los buenos, que fazen bien a sus amigos et que muestran en ello su bien fazer. (p. 255)

(17) Et llamólo el gato, et díxole: - ¿Por qué non te llegas a mí, el mi amigo que tan grant merçed me feziste? Ca yo he grant sabor de fazer gualardonar el bien que me as fecho, et darte he yo a commer el fruto de tu obra. Pues llégate a mí et non temas, ca non amo más a mí que a ti. (p. 271)

(18) Dixo Catra: [...] Et por lo que yo tengo en el coraçón conosco lo que tú tienes en el tuyo. Et non me es bien la tu conpaña, ca nunca vez te nenbrarás de lo que fize $a$ tu fijo, nin yo de lo que tu fijo fizo al mío, que non se nos muden los coraçones.(p. 276)

(19) (DEL REY ÇEDERANO ET DEL SU ALGUAZIL BELED ET DE SU MUGER ELBED) (p. 279)

(20) Esto que tú viste, señor, es tu muerte et perdimiento de tu regño, ca tornará en tus enemigos. Et esto non lo puedes desviar en guisa del mundo si non matares a Helbed, tu más honrada muger, madre del tu más amado fijo Genbrir, et a Genbrir su fijo, et el fijo de tu hermana que tú mucho amas, et a Belet, tu privado alguazil, et a tu escrivano que sabe tus poridades: et que quebrantes la tu mejor espada del tu mayor presçio, et que mates el tu elefante blanco que cavalgas, et a los otros dos elefantes presçiados, et el tu buen cavallo corredor et a Cainerón el philósopho. Desí que fagas poner la sangre déstos en una tina, et que te bañes en ella siete vezes, et que estemos nós enderredor de ti, et que te escantemos fasta que te mundifiquemos de los pecados que feziste, porque meresçes de Dios perder el reino et $t u$ honra. (p. 282)

(21) Mas aquí está Caimerón: muéstrale tu fazienda et demándale consejo, que es sabio destas cosas, et es otrosí dellos: et nós non le sospechamos que te dé leal consejo, et pregúntale por lo que viste en sueños: et si él te mandare lo que los otros te mandaron, fazlo: et si te mandare ál, verás que aquellos mentirosos son tus enemigos que quieren desfazerte del tu reino. (p. 286) 
(22) Ca él le contó al rey estonçes toda su fazienda et su acaesçimiento. Et luego, acabada esta rogativa, fue el niño sano et guarido. Et mandó el rey dar aquellos ornamentos al religioso, et del su aver mucho más, et mandólo soltar, et pidióle que le perdonase lo que le mandara fazer. (p. 321)

(23) Desí fízome ir al su rey, et mostróme razonar con él, et nenbróme a le dezir porque me ovo merçed, et creó lo que le dixe, non pensando en ello nin sabiendo en qué fenesçería mi fazienda: mas fue cosa que me puso Dios en coraçón, et me Él fizo dezir, de guisa que gané amor de aquel rey con quien nunca avía fablado. (p. 333)

(24) [E]n esto calló el rey. Et dixo el filósofo: - Señor, ayas poder sobre las mares, et dete Dios mucho bien con alegría, et goze tu pueblo contigo, et ayas buena ventura; ca en ti es acabado el saber et el seso et el sufrimiento et la mesura et el tu perfecto entendimiento. (p. 354)

Como puede observarse, el autor (traductor) alterna muy frecuentemente ambas estructuras en su discurso, sin que, en principio, podamos encontrar una razón evidente para el uso de una u otra. Así, por ejemplo, en (1) parece más que difícil explicar por qué en dos ocasiones aparece la su vida y en otras dos se recurre simplemente a su vida. Los distintos investigadores que han analizado esta construcción han intentado, no obstante, encontrar una motivación para el uso de una u otra secuencia. A continuación, me centraré en el análisis de los ejemplos con el fin de demostrar si estamos ante variantes invisibles o si hay razones sintácticas, semánticas o pragmáticas que condicionen el uso de esta construcción.

\section{UN BREVE Y NECESARIO PARÉNTESIS: LA CONSTRUCCIÓN UN/ UNA + POSESIVO + NOMBRE}

Antes, aunque no es esta la construcción objeto de mi trabajo, quiero comentar que también es posible encontrar en el Calila casos de artículo indefinido + posesivo (13 en total: 2 de una su y 11 de $u n s u$ ), siempre con el posesivo $s u^{8}$.

(25) O non sea atal commo el ome que dezían que quería leer gramática, que se fue para un su amigo que era sabio. Et escrivióle una carta en que eran las partes de fablar. Et el escolar fuese con ella a su posada, et leyóla mucho, pero non conoçió nin entendió el entendimiento que era en aquella carta. (p. 92)

(26) El hombre que quería robar a su compañero: Et dizen que un espeçiero tenía sísamo, él et un su conpañero, et cada uno dellos tenía una buxeta dello, et non lo avía en toda esa tierra más de lo que ellos tenían. Et el uno dellos pensó en su coraçón que furtase lo de su conpañero. Et puso una señal sobre una buxeta en que estava el sísamo de su conpañero por que, de que veniese de noche a lo furtar, que la conoçiese por la señal. Et puso una sávana blanca ençima dello por señal. Et descobrió esto que quería fazer a un su amigo por que fuese con él de noche a lo furtar. Et el otro non quiso ir con él fasta que le prometió de darle la meatad dello. Et después su conpañero vino et falló la sávana cobierta sobre su sísamo. Et dixo: - Verés qué ha fecho

\footnotetext{
${ }^{8}$ En otros textos de la época se encuentra también, aunque con menor frecuencia, esta construcción con posesivos de primera y segunda persona: et esto que lo fazedes por razon de una mi carta en que vos yo embie mandar que, (1279, Anónimo: Normativa [Documentos de Alfonso X dirigidos a Castilla la Vieja]); aya yo tanta gracia de ti si mas non que lieue yo de ti algunos besos. cuemo los leuarie de ti una tu hermana (1275, Alfonso X: General Estoria. Segunda parte).
} 
mi conpañero por guardar mi sísamo de polvo; púsole esta sávana, et dexó lo suyo descobierto. (p. 94)

(27) Et esta muger avía un amigo, et era alcahueta entre ellos una muger de un su vezino. Et mandóle que fuese a su amigo, et que le feziese saber que su marido] [era] conbidado et que non tornaría sinon beudo et grant noche. (p. 139)

(28) Dixo Digna: - Dizen que un cuervo avía su nido en un árbol en el monte, et avía çerca dél una cueva de una culebra; et cada que sacava los pollos comíagelos la culebra. Et después que gelo ovo fecho muchas de vezes, ovo muy grant cuita et querellóse $a$ un su amigo de los lobos çervales. (p. 143)

(29) Et prometióle que tornaría a él, et salióse ende et guisó cómmo le tomó un su fijo pequeño que avía; et levólo para su casa, et escondiólo. Desí tornóse para él, et el otro preguntóle: - ¿Viste mio fijo? (p. 176)

(30) Díxol'su amigo: -Yo te faré una seña tan blanca commo la luz de la luna, et faré en ella unas pinturas; et quando las tú vieres, saldrás a mí, et esta será señal entre mí et ti. Et plóguela a el[la] desto que l' dixo. Et oyólo un su siervo della, et aprísolo, et encubriólo en su corazón. (pp. 184-185)

(31) Et enbió el rey de los elefantes sus mandaderos et sus atajadores a recabdar agua. Et tornóse para él un su mandadero et díxole que en un lugar señalado fallara una fuente que es llamada la fuente de la luna. (p. 231)

(32) Et después que oyó el rey al cuervo esto dezir, dixo a un su privado: -¿Qué te paresçe que fagamos a este cuervo? (p. 238)

(33) Desí la muger del galápago fue muy triste por la tardança de su marido, et quexóse a una su comadre: et díxole la comadre: - Non te acuites, que me dixeron que tu marido está en la ribera de la mar et que ha por amigo un ximio: et están anbos comiendo et solazándose. (p. 254)

(34) Et tenía çerca de sí un su vezino que le dezían anxahar, et oyóle dar bozes et alaridos. Et salió a ella et díxole: (p. 301)

(35) Et pensó de se ir et dexarlos, et arrimóse a un árbol que estava en medio de la çibdat, et començó de catar a los que pasavan por aí. Et pasó por aí una dueña fijadalgo, cavallera en su mula, et sus mugeres en pos della et sus criados, et vídolo aí ser: et desconosçiólo et entendió que era omne estraño, et vídolo tan fermoso et tan apuesto, et así tan cuidoso, et ovo conpassión dél. Et desque llegó a su posada, enbió una su muger a él: et la muger fue a él, et fallólo adormeçido del cuidado que tenía, et despertólo, et díxole: - Mi señora doña fulana, muger de don fulano, me enbía a ti, et ruégate que la vayas ver a su posada. (p. 327)

(36) Dixo el philósofo: -Dizen que una paloma sacava palominos de un su nido que avía en una palma muy alta. Et la paloma por mudar su nido allí avía grant trabajo, tanto era de alta. (p. 352)

Esta secuencia alterna con construcciones solo con posesivo. Hay que destacar que no se encuentra en toda la obra ninguna construcción con artículo indefinido, que aquí todavía es numeral, con posesivo pospuesto, tipo un amigo mío, un amigo suyo. Respecto a esta estructura, Company (2009a: 772) afirma que el posesivo tónico pospuesto con función adjetival no se localiza hasta inicios del siglo XIV. Se trata, de hecho, de una construcción muy poco frecuente en el siglo XIII pero no podemos decir que sea inexistente; he realizado una búsqueda en el CORDE en el tramo cronológico que va de 1240 a 1280, por tomar un muestreo de la lengua de la época, y he podido localizar solo estos cuatro ejemplos: 
(37) E el entregome con su carta e con un cavallero suyo de Toledo e desi yo entregue por carta de don Roy Lopez a Garcia Perez Gorgogi de las vinnas que avie en la Sierra de Cordova e de las casas e de las vinnas e de la uerta que el avie en Fornachuelos e de diez yugadas que avie en Aymont a don Roy Lopez o a quien el mandasse. (1267, Anónimo: Sentencia de pleito [Documentos de Alfonso X dirigidos a Andalucía])

(38) e es aun tenedor dello e metiome por mano a uncavallero suyo que quando el pan fuesse cogido quel entregasse de la heredat. (1267, Anónimo: Sentencia de pleito [Documentos de Alfonso X dirigidos a Andalucía])

(39) Mas assí como dize en el Génesis, Elifat, que fue el primero fijo de Esaú, e fízolo en una barragana suya, e ovo un fijo a que llamavan por nombre Amalech; (c 1275, Alfonso X: General Estoria. Primera parte)

(40) e diol ella por mugier a unasobrina suya fija de hermana de su padre, (c 1275, Alfonso X: General Estoria. Primera parte)

Sin embargo, sí es relativamente frecuente el uso del posesivo tónico pospuesto, cuando el artículo es determinado ${ }^{9}$ :

(41) Et otrossi mando e otorgo que elomne mio non tome nin robe nenguna cosa. (1255, Anónimo: Carta Real)

(42) Quien dara guarda a la boca mia \& en sennalamiento cierto sobre los mios labros que non caya yo por ellos. \& me destruya la mi lengua. (1280, Alfonso X: General Estoria, Cuarta parte)

(43) El nescio por los sus falsos sabores, que cresce lanescedat suya e la su vileza. (1250; Anónimo: Bocados de oro)

(44) Sy algun otor o defendedor dyxiere / que lacosa suya le fue criada o fecha, (1251 1285, Anónimo: Fuero de Úbeda)

(45) Pero la voluntat teniéla confortada, ca es elsolaz suyo melezina provada. (1246 1252, Berceo, Gonzalo de: Los Milagros de Nuestra Señora )

(46) \& su testimonjo ffinca valedero. pues elnonbre suyo es el de dios. (1260, Anónimo: Espéculo de Alfonso X)

Por otra parte, y como señala esta autora (Company, 2009a: 869), los sintagmas con artículo indefinido ante posesivo «se caracterizan por seleccionar poseídos humanos [en el texto analizado: un su amigo, un su compañero, una su comadre, una su muger...], emplearse en fragmentos narrativos [como los señalados en 25-36] y mantener el rasgo etimológico de cuantificación propio del numeral uno [valor fundamental de un/una en esta época]». Solo en uno de los casos se incumple uno de estos requisitos; se trata del ejemplo (36) en el que el poseído es inanimado: "su nido». No es lo habitual pero hay algún ejemplo más en la época, por lo que no es posible afirmar que el rasgo [+ humano] y ni siquiera el rasgo [+ animado] sea un requisito indispensable para la utilización de esta secuencia. Propongo, a continuación, algunos ejemplos de este uso:

\footnotetext{
${ }^{9}$ Los ejemplos que presento son únicamente una muestra de los localizados en el tramo cronológico 1240-1280.
} 
(47) Escrivio el en una su carta quando conquiso todas las villas: (c 1250, Anónimo: Libro de los buenos proverbios que dijeron los filósofos y sabios antiguos)

(48) que dixo en un su libro que la planeta es atada con el Sol; (1254 - 1260, Anónimo: Judizios de las estrellas)

(49) tomaron allí una cocadriz, e pusiéronla en un su tiemplo que dizién Beseo, (c 1275, Alfonso X: General Estoria. Primera parte)

(50) Onde fallamos que cuando mataron a Lasón de Licia un su can de duelo que ovo non quiso comer, (c 1275, Alfonso X: General Estoria. Primera parte)

(51) que los el destruyrie; una su torre que auien y muy fuerte. (c 1275, Alfonso X: General Estoria. Segunda parte)

(52) llegaron al Rey Nabuchodonosor. era ell en una su tierra que dizien xem (c 1280, Alfonso X: General Estoria. Cuarta parte)

Pese al interés que despierta la secuencia un/una + posesivo + nombre, tengo que dejarla de lado pues supera las expectativas de un trabajo de las dimensiones de este y considero que merece un estudio más detallado con el que puedan determinarse con rigor cuáles son sus condiciones de uso ${ }^{10}$. He creído conveniente, sin embargo, traerla a colación y mostrar con unas brevísimas pinceladas su aparición en el Calila ya que se trata de una estructura con una semejanza muy significativa con la construcción que estoy analizando y además supone una muestra más de la vacilación que en este texto medieval presentan las estructuras posesivas.

\section{LA SECUENCIA ARTÍCULO + POSESIVO + NOMBRE COMO VARIANTE INVISIBLE}

Si volvemos a la tabla 1, se observa que la estructura artículo + posesivo + nombre se utiliza básicamente para un solo poseedor y en singular. En un trabajo anterior (Serradilla, 2007) afirmaba que uno de los posibles valores que aporta la construcción con artículo en español actual, en las áreas en las que pervive, es marcar la unicidad. Este valor podría apuntarse ya en la época medieval pues, vistos los usos en los que hay varios poseedores o un solo poseedor, observamos que solo en 5 ocasiones se usa la estructura con artículo cuando el posesivo se refiere a más de un poseedor $(8,06 \%)$. Esto podía orientarnos hacia el hecho de que no estemos ante una variante invisible sino ante un uso motivado o al menos condicionado por el número de poseedores. No obstante, aunque los ejemplos son escasos, están documentados a lo largo de toda la época medieval ${ }^{11}$.

\footnotetext{
${ }^{10}$ Para el estudio de la situación de esta estructura en español clásico peninsular, véase Gómez Seibane (en prensa) y para el análisis de la continuidad y los valores de esta estructura en el español americano actual, conviene acudir a los trabajos de Pato (2002) y Palacios (2004).

${ }^{11}$ A continuación se muestran los datos de apariciones de la construcción «artículo + posesivo + nombre» recogidos en la base de datos ADMYTE, que ya analicé en Serradilla (2003):

$\begin{array}{llll}\text { EL MI - 151 } & \text { LA MI - 199 } & \text { LOS MIS - 90 } & \text { LAS MIS - 79 } \\ \text { EL TU - 353 } & \text { LA TU - 497 } & \text { LOS TUS - 185 } & \text { LAS TUS - 110 } \\ \text { EL SU - 966 } & \text { LA SU - 1293 } & \text { LOS SUS - 491 } & \text { LAS SUS - 370 } \\ \text { EL NUESTRO - 219 } & \text { LA NUESTRA - 140 } & \text { LOS NUESTROS - 120 } & \text { LAS NUESTRAS - 53 } \\ \text { EL VUESTRO - 102 } & \text { LA VUESTRA - 169 } & \text { LOS VUESTROS - 64 } & \text { LAS VUESTRAS - 27 }\end{array}$

Como puede observarse, predominan los casos de singular y de un solo poseedor pero no podemos desdeñar la presencia de los ejemplos en los que hay varios poseedores o el posesivo está en plural, ya que no se trata de casos esporádicos sino que existe una documentación significativa.
} 
A continuación se recogen los ejemplos en los que se hace referencia a varios poseedores en esta obra:

las sus:3

la nuestra:1

las nuestras: 1

(53) Et plazíales más de aquello que de ninguna juglaría nin de otro plazer, ca tenién que non era ninguna cosa de las que ellos se trabajavan de mejor premio nin de mejor galardón que aquello de que las sus ánimas trabajavan et enseñavan. (p. 89)

(54) Et tove que traía algo en él para quien le entendiese, et rogué a Dios por los oidores dél, que fuesen entendedores de las sus sentençias et del meollo que yaze en ellas. (p. 121)

(55) Dixo el rey al filósofo: [...] Et en esto he oído atan maravillosas et tantas fazañas, que es asaz conplimiento para se guardar omne et de se aperçebir de los mezcladores et de los terreros, et de los falsos en las sus falsedades et sus engaños que fazen. Et los omnes entendidos deven perseguir las mentiras et falsedades, et perseguir los mezcladores et escodrinar tales cosas; (p.178)

(56) Et este atal faz mayor dapño a los enemigos que los mucho[s] esforçados et valientes. Ca el consejo que de ti nasçió, seyendo uno dellos, fizo mayor dapño en matar nuestros enemigos que eran tantos et tan dapñosos, que la nuestra fuerça de todos: et de lo que más me maravillo de ti, cómmo moraste con ellos et sofriste tanto pesar quanto veías et oías, et non te moviste a ninguna palabra. (p. 251)

(57) Et fío por vuestro saber en vos yo consejar et vos amar, maguer me dize mi alma que non me creeredes. Mas, quando yo me remienbre que las nuestras almas de todas las bestias son colgadas de la vuestra, non puede ser que non faga lo que devo, maguer non me lo preguntedes et maguer me yo tema que non me lo creades. (p. 148) ${ }^{12}$

En busca de todos los parámetros que puedan ser decisivos para la utilización de una u otra construcción, me he fijado en distintas situaciones semánticas, sintácticas y pragmáticas que puedan propiciar la aparición de esta secuencia; así, en primer lugar, he prestado atención a la frecuencia de aparición de la estructura analizada dependiendo de si se encuentra en un sintagma nominal o en un sintagma preposicional. La presencia en construcciones preposicionales es minoritaria: 24 casos de un total de 62 apariciones $(38,7 \%)$, distribuidas de la siguiente forma:

TABLA $2^{13}$

\begin{tabular}{|l|l|l|l|}
\hline la mi:1 & el mi:2 & la tu:4 & el tu:5 \\
\hline la su:4 & el su:5 & las sus:2 & las tus:1 \\
\hline
\end{tabular}

\footnotetext{
${ }^{12}$ Es posible que en este caso estemos ante un paralelismo: las nuestras almas - la vuestra.

${ }^{13}$ Con las demás formas posesivas no se encuentra documentación de esta estructura.
} 
Este uso minoritario puede deberse a un intento de evitar varios elementos átonos seguidos: preposición + artículo. Propongo a continuación algunos de los ejemplos documentados:

(58) Et tovo por cosa vergonçosa de tornar a su señor el rey con tan mal recabdo, et quexóse desto a los filósofos de los reyes de India. Et ellos dixéronle que eso mesmo fallaran ellos en sus escripturas que él avía fallado, et, propiamente, el entendimiento de los libros de la su filosofía et el saber que Dios puso en ellos son los cuerpos, et que la melezina que en ellos dezía son los buenos castigos. (pp. 100-101)

(59) Desí puso en este libro lo que trasladó de los libros de India: unas questiones que fizo un rey de India que avía nonbre Diçelem: et al su alguazil dizían Burduben. (p. 102)

(60) Et estonçe demandó el religioso un açadón, et tráxole al huésped, et yo estando en otra cueva ajena oyendo lo que dezían. Et avía en la mi cueva mill maravedís, et yo non sabiendo quien los posiera aí, enpero yo meneávalos et alegrávame] con ellos quando quier que me venía emientes. Así qu' el huésped cavó la cueva fasta que llegó a ellos, et sacólos. (p. 213)

(61) Dixo el asno: - Pues vayamos allá, que si por ál yo non lo fiziese sinon por la cobdiçia del tu amor, esto me faría allá ir contigo. (p. 260)

(62) Mas aquí está Caimerón: muéstrale tu fazienda et demándale consejo, que es sabio destas cosas, et es otrosí dellos: et nós non le sospechamos que te dé leal consejo, et pregúntale por lo que viste en sueños: et si él te mandare lo que los otros te mandaron, fazlo: et si te mandare ál, verás que aquellos mentirosos son tus enemigos que quieren desfazerte del tu reino. (p. 286)

No obstante, habría que cuestionarse hasta qué punto esto puede considerarse un factor determinante o si, simplemente, hay que tener en cuenta que es más frecuente encontrar la estructura posesivo + nombre en sintagmas sin preposición ya que en este caso se incluyen tanto los sujetos como los complementos directos, los atributos o los predicativos, con lo que la frecuencia es necesariamente mayor. Precisamente, respecto a la función de los sintagmas en los que aparece esta construcción, recojo las estadísticas que para el siglo XIII presenta Company (2009a: 808):

TABLA 3

\begin{tabular}{|l|l|}
\hline Sujeto: & $29 \%$ \\
\hline OD: & $22 \%$ \\
\hline OI: & $3 \%$ \\
\hline Predicado: & $8 \%$ \\
\hline Circunstancial: & $36 \%$ \\
\hline Otros & $2 \%$ (FN en función de tópico y vocativos) \\
\hline Total de apariciones & 431 \\
\hline
\end{tabular}

En el Calila las proporciones varían mucho respecto a las presentadas por Company: 
TABLA 4

\begin{tabular}{|l|l|}
\hline Sujeto: & $35,49 \%$ \\
\hline Atributo: & $4,84 \%$ \\
\hline CC: & $12,9 \%$ \\
\hline CD: & $22,58 \%$ \\
\hline CI: & $1,61 \%$ \\
\hline CN: & $14,51 \%$ \\
\hline Predicativo: & $1,61 \%$ \\
\hline CRP: & $4,84 \%$ \\
\hline Vocativo & $1,61 \%$ \\
\hline Total de apariciones & 62 \\
\hline
\end{tabular}

Como puede observarse, esta construcción aparece, sobre todo, cuando el sintagma nominal cumple la función de sujeto y, en segundo lugar, la de CD. Según los datos de Company, es en el CC, con un $36 \%$, donde la estructura artículo + posesivo es más frecuente y, de hecho, es en sintagmas con esta función en los que más crece a lo largo de los siglos. No ocurre, así, en la obra analizada. En todo caso, dado que puede aparecer en SN que cumplen funciones muy diversas, parece evidente que la función no determina el uso de la construcción con o sin artículo.

Hay una frase de Company en sus conclusiones (2006: 103) que convendría analizar:

En primer lugar, más allá de la indudable arbitrariedad del signo lingüístico, existe una relación solidaria entre su lado formal y su lado semántico, de manera que a construcciones formalmente marcadas y de distribución restringida cabe esperar una caracterización semántica y pragmática también muy marcada y especializada.

Esta autora espera, por tanto, que se den determinadas circunstancias que justifiquen la presencia de artículo + posesivo en el discurso. Así, por ejemplo, busca una motivación en la distancia con el referente (Company, 2006: 82):

CUADRO 1

TABLA 5

\begin{tabular}{|c|c|c|c|}
\hline \multicolumn{3}{|c|}{ Distancia de anclaje referencial del poseedor } \\
\hline \multicolumn{2}{|c|}{ Artículo + Posesivo } & \multicolumn{2}{c|}{ Posesivo simple } \\
\hline Corta & Larga & Corta & Larga \\
\hline $66 \%$ & $34 \%$ & $84 \%$ & $16 \%$ \\
$(402 / 611)$ & $(209 / 611)$ & $(168 / 200)$ & $(32 / 200)$ \\
\hline
\end{tabular}

Se refiere Company a la distancia con el referente en el caso de $s u$. No se analiza el referente de $1^{\mathrm{a}}$ y $2^{\mathrm{a}}$ persona pues este no está en el enunciado sino en la enunciación, obvia- 
mente. «Distancia corta» indica que el referente está en la misma oración o en la anterior, mientras que «distancia larga» hace alusión a un referente situado a dos o más oraciones de distancia. A continuación, presento los datos con los que cuento:

TABLA 6

\begin{tabular}{|c|c|c|c|}
\hline la su: 13 & el su: 8 & las sus: 3 & los sus: 1 \\
\hline \multicolumn{4}{|c|}{ Artículo + Posesivo } \\
\hline \multicolumn{3}{|c|}{ Corta } & \multicolumn{2}{c|}{ Larga } \\
\hline $21 / 25$ & $84 \%$ & $4 / 25$ & $16 \%$ \\
\hline
\end{tabular}

Obsérvese que las estadísticas no coinciden con las presentadas por Company; es más, curiosamente, los porcentajes son los mismos que ella presenta para la construcción sin artículo. Dada la variación existente, no me atrevería a afirmar que la distancia con el referente pueda ser una de las causas para usar una u otra construcción, ya que, independientemente de la construcción, lo más habitual es que posesivo y referente no queden muy lejanos en el acto comunicativo.

Por otra parte, Company (2006: 94) hace referencia también a que la construcción artículo + posesivo indica una integridad semántica: «En todas las correlaciones se hace transparente que el vínculo de integridad semántica y complementariedad referencial que establecen poseedor y poseído es una constante y una propiedad definidora de la construcción».

Continúa con su justificación:

Dos rasgos gramaticales apoyan esta interpretación de las construcciones artículo + posesivo. 1) Por una parte, como se aprecia en varios de los ejemplos de arriba, con mucha frecuencia el poseído repite léxicamente la raíz morfológica del poseedor: rey el su reinado, rey el su regno, señores el su señorío [...], lo cual, icónicamente, confirma el carácter inherente del poseído para el poseedor, esto es, la integridad semántica entre ambos, ya que repite no sólo el significado, sino también buena parte del significante del poseedor, es decir, un efecto de complementariedad doble: referencial y formal, contribuyendo con tal repetición a intensificar el vínculo entre poseedor y poseído. 2) Por otra parte, el poseedor y la construcción poseída aparecen con mucha frecuencia coordinados mediante la conjunción copulativa $e(t) / y[\ldots]$, o bien, con menor frecuencia, el poseído opera como un adnominal o un complemento comitativo del poseedor [...], todo lo cual puede interpretarse como que poseedor y poseído constituyen una sola unidad conceptual y establecen un vínculo que se presenta como indisoluble en el discurso narrado.

Desde mi punto de vista, esta relación de integridad semántica es incuestionable, pero vayamos por partes: en cuanto a la repetición formal, en el Calila solo se ve en un caso «el falso en las sus falsedades» $\mathrm{y}$, respecto a la coordinación con la copulativa, los datos contradicen esta afirmación. Esto no quiere decir que no haya integridad semántica sino que no se representa formalmente con ninguna marca determinada.

Por otra parte, en cuanto al poseedor, este suele ser humano o animal -recuérdese que estamos ante una colección de cuentos protagonizados por animales- y rele- 
vante en la narración, pero no más que cuando se usa solo el posesivo. No es la misma situación que encontraremos en los documentos jurídicos y administrativos de los siglos XV al XVIII estudiados por Gómez Seibane (en prensa: 21):

[...] se han observado algunas diferencias, relacionadas con la actualización y modificación del poseído, que parecen depender del tipo de poseedor. En efecto, cuando los poseedores son la autoridad real, la religiosa o la civil el recurso a la estructura artículo definido+posesivo responde a las características semánticas anteriormente descritas y, en la mayor parte de los testimonios, aparece sin modificación - y, si la presenta, es redundante- - Por añadidura, en la referencia a este tipo de poseedores se ha advertido la presencia de artículo definido+posesivo en expresiones formularias con distinto grado de rutinización.

Cuando el poseedor es un individuo particular, en cambio, el poseído debe acompañarse primero de artículo definido (es decir, actualizarse) y, en próximas apariciones, cuando ya es una realidad conocida por el receptor, puede focalizarse con una construcción de artículo definido+posesivo.

La realidad linguiística nos permite observar una evolución en el uso motivado de esta secuencia, a la que después volveré al analizar los valores pragmáticos. Aunque, en este caso, la variante parezca ser invisible, eso no quiere decir que siglos después, como señalaba el profesor Barra, no se haga visible y motivada.

En mi búsqueda de posibles causas para el uso de la construcción artículo + posesivo ante nombre he hecho un recuento de todos los nombres que participan de esta construcción en el Calila.

TABLA 7. SUSTANTIVOS QUE APARECEN EN LA ESTRUCTURA ART. + POS. + NOMBRE

\begin{tabular}{|c|c|c|}
\hline alguacil & almas & amigo \\
\hline amor & andançia & ánimas \\
\hline aver & cara & cavallo \\
\hline cima & compañia & consejo \\
\hline corazón & costumbre & criazón \\
\hline cuerpo & cueva & cuidado \\
\hline elefante & enseñamiento & entendimiento \\
\hline espada & estentinos & falsedades \\
\hline fazienda & fijo & filosofía \\
\hline forma & fuerça & intençión \\
\hline mayordomo & merced & mesura \\
\hline muerte & nombre & paciencia \\
\hline piadat & presçio & privanza \\
\hline reino & rey & saber \\
\hline sentençias & tachas & talente \\
\hline tristeza & vasallo & ventura \\
\hline vida & vientre & \\
\hline
\end{tabular}


En Serradilla (2007) señalaba que esta construcción se ha conservado en la actualidad solo cuando realmente hay un poseedor y algo poseído y no cualquier otra relación que pueda indicar el posesivo; ${ }^{14}$ no obstante, con los datos que se documentan en esta obra, no parece existir limitación alguna.

Company (2009a) habla de poca productividad léxica, en el sentido de que casi siempre son las mismas palabras las que aparecen en esta construcción. En este caso, sin embargo, observamos en la tabla 7 una gran variedad de nombres, hasta 50; y se puede comprobar que los poseídos pertenecen a diferentes clases léxicas:

\section{Abstractos: 27 \\ Colectivos: 1 \\ Humanos: 6 \\ Concretos: 16}

Dice Company (2009a) que, en cantidad, predominan los no concretos (87\% en el XIII), teniendo en cuenta que agrupa bajo esta denominación a los abstractos, locativos y colectivos. Con los datos de la obra analizada, es verdad que predominan los no concretos pero no en esa proporción: $45,16 \%$ frente al 35,48\%. Es posible que el tipo de texto pueda determinar los resultados de las estadísticas, pero, de nuevo, encontramos que el hecho de que un nombre sea concreto o abstracto no parece ser determinante a la hora de elegir una u otra construcción.

He intentado hacer una clasificación un poco más detallada de los nombres que participan en esta estructura, por si es posible observar alguna posible motivación para el uso de esta construcción:

Nombres que indican una relación de posesión o pertenencia (frecuentemente se trata de objetos o animales que pertenecen al poseedor): aver, cavallo, cueva, elefante, espada, fazienda, forma, nombre, presçio, reino.

Nombres de persona: alguacil, amigo, compañía, fijo, mayordomo, rey, vasallo. En todos los casos se establece una relación de dependencia.

Nombres que indican parentesco: fijo

Partes del cuerpo (posesión inalienable): almas, ánimas, cara, corazón, cuerpo, estentinos, vientre.

Nombres que indican cualidades o características del poseedor: fuerça, merced, piadat, talente, tachas.

Nombres que indican una relación en la que el referente es el experimentante de la acción: amor, andançia, consejo, enseñamiento, muerte, sentençias, vida.

Nombres que se refieren a conceptos abstractos: costumbre, criazón, cuidado, enseñamiento, entendimiento, falsedades, filosofía, intençión, privanza, saber.

En fin, ante la nómina presentada, puede observarse que los nombres que participan son de tipo muy diverso y no parece que haya ninguna subclase semántica que condicione la aparición de esta secuencia.

\footnotetext{
${ }^{14}$ Véase para la jerarquía en la relación prototípica de la posesión el trabajo de Carmen Picallo y Gema Rigau (1999): poseedor, agente, tema (o paciente).
} 
Precisamente para poder establecer una comparación, he investigado también si estos mismos nombres participan en la construcción posesivo + nombre. Los resultados son los siguientes: de los 50 nombres analizados, solo 11 no aparecen en esta construcción (22\%): ánimas, cara, criazón, elefante, filosofía, forma, presçio, paciencia, estentinos, intençión y sentençias. Además, hemos de tener en cuenta que los cuatro últimos nombres no presentan más apariciones en todo el documento, por lo que la proporción baja aún más (14\%).

Por tanto, vemos que la gran mayoría de los nombres analizados pueden aparecer en ambas construcciones. Además he buscado en otros textos de la época las posibilidades constructivas de estos nombres y, en general, es habitual documentarlos en expresiones con posesivo ${ }^{15}$ :

(63) Todas aquellas cosas que alguno por su anima mandare dar, sea muy firme. (1218-c 1250, Anónimo: Fuero de Zorita de los Canes)

(64) Alli en somo daquel mont ensennando de su philosophia las compannas que a ell uinien (1275, Alfonso X, General Estoria. Segunda parte $)^{16}$

Más extraña resulta la construcción artículo + nombre + posesivo, que en el siglo XIII no se localiza con excesiva frecuencia aunque hay algunos casos como el siguiente o los que ya mostraba en el apartado 3 :

(65) Hanc donationem facio por la anima mea de todos mios parientes que merezcamos e que seamos parçoneros en todos los beneficios del monasterio deuant dito. (1245, Anónimo: Donación al monasterio de (rache $)^{17}$

La conclusión a la que se puede llegar después de este análisis es que los nombres que pueden llevar artículo + posesivo también se pueden construir con posesivo exclusivamente. Esto ya nos da una pista, pues sabemos que no hay nada en la naturaleza de los sustantivos analizados que provoque la primera de las construcciones y excluya la no marcada. Company (2006: 103) afirma, sin embargo:

[...] la elección nunca es al azar, sino que está determinada tanto por el significado invariante o constante de las formas, que en gran medida es consecuencia o dependiente del significado etimológico originario, como por el contexto en que la forma aparece, cuanto, desde luego, por el propósito comunicativo de los hablantes en una situación social y cultural determinada.

\footnotetext{
${ }^{15} \mathrm{El}$ único sustantivo que no he encontrado con posesivo en textos del XIII es elefante; se trata de algo lógico, pues, obviamente, en la España medieval no era habitual poseer elefantes.

${ }^{16}$ También, obviamente, hay construcciones solo con artículo pero lo que me interesa más es la comparación con la construcción con posesivo ya que la estructura que estoy analizando es más posesiva que actualizadora, por esa razón, a veces, en distintas ediciones de obras medievales se elimina el artículo y no suele eliminarse el posesivo.

${ }^{17}$ En este caso estamos ante una expresión de carácter formulario y hay dos opciones de lectura: o bien falta la conjunción copulativa $y$, o bien el posesivo estaría de más, y el texto se referiría solo al «alma de mis parientes». Como he avanzado, se trata, de todas formas, de una construcción relativamente poco frecuente en la época.
} 
Hasta ahora no he encontrado ninguna motivación, salvo la preferencia, y no siempre, por el uso con poseedores singulares, pero veamos más detenidamente si el propósito comunicativo o la situación pragmática pueden condicionar, de alguna manera, el uso de esta construcción en el Calila.

En Serradilla (2007) comentaba que uno de los posibles valores de esta construcción en las áreas en las que aún permanece viva es la de marcador del foco discursivo, del elemento más relevante. En esta misma línea se inscriben algunas de las afirmaciones de Moral del Hoyo (2006: 368). Esta autora analiza una tradición discursiva medieval muy concreta, la de las cartas de venta, y comenta cómo la construcción artículo + posesivo permite destacar pragmáticamente el elemento fundamental del discurso:

Los roles cubiertos por las instancias comunicativas no revisten igual importancia o compromiso en el discurso. En este sentido, el vendedor se coloca en un eje primordial. Todo lo que afecte a esta instancia puede encontrar marcas lingüísticas que refuercen su dimensión performativa: es el caso de la secuencia artículo + posesivo. Lo encontramos afectando al bien que entra en el negocio y sobre el cual se expresa la posesión (1346 el nuestro solar, 1448 la mi parte e mentad de la rueda). Se trata de una secuencia para cuyo uso literario, en los siglos XIV y XV suele aducirse «una clara información estilística, semántica y pragmática» por contraste con su supuesto uso en modelos más inmediatos. Pues bien, la presencia de esta peculiar ocurrencia en un contexto tan determinado nos hace suponer que, aun aceptando que «en la lengua jurídica el artículo antepuesto tiene unos patrones de frecuencia y de uso bien delimitados» el valor pragmático hace que se perpetúe en algunos de ellos como una secuencia marcada hacia la instancia comunicativa del vendedor ${ }^{18}$.

Esto nos lleva a poder afirmar que en este tipo de texto el autor usa esta fórmula de forma consciente y no se trataría, por tanto, de una variante invisible. Me gustaría citar de nuevo, por último y en este mismo sentido, el trabajo de Sara Gómez Seibane (en prensa), quien analiza también textos de una determinada tradición discursiva, en un área geográfica muy determinada: documentos municipales reguladores de la vida en la villa y de sus instituciones de Bilbao, Portugalete y Lekeitio desde la segunda mitad del siglo XV hasta finales del siglo XVIII ${ }^{19}$. En los textos analizados, la autora observa cómo la presencia de la secuencia artículo+posesivo parece venir propiciada por la naturaleza del poseedor:

[...] el empleo de artículo+posesivo se documenta en más de la mitad de sus apariciones cuando el poseedor es el rey (la su alteza), fundamentalmente a través de sus posesiones ( $\mathrm{al} \mathrm{mi}$ consejo, los mis regnos e sennorios, la mi rubrica), personas vinculadas a su figura (los mis vasallos, del mi tesorero) o características de su persona (la su justicia, la mi yra) (Gómez Seibane, en prensa: 9).

De esta forma, esta estructura serviría para destacar el poder y la autoridad del poseedor, con lo que observamos, de nuevo, que tiene un valor pragmático claro como marcador del foco discursivo o del elemento más relevante. En el texto que estoy analizando,

\footnotetext{
${ }^{18}$ Los entrecomillados de la cita pertenecen a Gloria Clavería (1993).

${ }^{19}$ En el caso de Bilbao se incluyen textos como testamentos, inventarios o declaraciones de testigos de los siglos XVI a XVIII.
} 
sin embargo, unas veces el poseedor es quien habla, otras veces es el interlocutor o alguien de quien se habla y, en ambos casos, puede ser un personaje de cualquier categoría. Así, en el siguiente ejemplo el poseedor es el rey:

(66) Ca él le contó al rey estonçes toda su fazienda et su acaesçimiento. Et luego, acabada esta rogativa, fue el niño sano et guarido. Et mandó el rey dar aquellos ornamentos al religioso, et del su aver mucho más, et mandólo soltar, et pidióle que le perdonase lo que le mandara fazer. (p. 321)

Pero en el que presento a continuación es una «dueña»:

(67) Quando el rey vido que lo fiziera tan aína, cuidó que era sabio et agudo, et mandól' dar algo et buenos paños. Et él dio a bever la melezina a la dueña, et luego, commo la bevió, fueron los sus estentinos despedaçados et murió. (p. 192)

En el siguiente es un «omne entendido»:

(68) Et non de se ve el omne entendido alegrarse por grand aver, nin aver pesar por lo poco; mas el su aver con que deve alegrar es su entendimiento. (p. 219)

En los siguientes son diferentes animales:

(69) [una culebra] Et echóse çerca de la fuente a semejança de triste et de pesante. Díxole una rana: - ¿Qué as, que estás triste? Dixo ella: - ¿Et cómmo non seré triste , que la mi vida non era de ál sinon de las ranas, et agora vínome grand ocasión, de guisa que non puedo comer nin tomar sinon las que me dan en limosna? (p. 249)

(70) Et llamólo el gato, et díxole: - ¿Por qué non te llegas a mí, el mi amigo que tan grant merçed me feziste? Ca yo he grant sabor de fazer gualardonar el bien que me as fecho, et darte he yo a commer el fruto de tu obra. Pues llégate a mí et non temas, ca non amo más a mí que a ti. (p. 271)

E, incluso, en este ejemplo los poseedores son un «señor» pero también un pariente y un extraño, por lo que vemos que la categoría del poseedor no parece ser relevante:

(71) Et dixo el cuervo: - Señor, sienpre me atove al tu buen enseñamiento en aconpañar al pariente et al estraño con mansedunbre, et siguiendo su sabor et consentiendo el su talente. (p. 251)

Esta realidad no tiene por qué contradecir las afirmaciones de Gómez Seibane; simplemente estamos trabajando con textos de diferente tipología y de distinta cronología. Téngase en cuenta que tanto Moral del Hoyo como Gómez Seibane analizan textos de unas épocas en las que esta construcción está en retroceso (siglos XIV y XV, la primera, y XV a XVIII, la segunda ${ }^{20}$ y, por tanto, su uso comienza a ser motivado.

\footnotetext{
${ }^{20}$ Según los datos de Company (2009a: 798), el siglo XIII es la época en la que más aparece la construcción analizada.
} 
La variante invisible comienza entonces a ser visible y remotivada; recuérdese, en este sentido, la evolución que proponía Barra Jover (2009a) y que recogía al principio de este trabajo.

En otra línea, he prestado atención al tipo de discurso en el que se inserta la construcción artículo + posesivo y en el texto que estoy analizando no he observado una mayor presencia relativa de esta secuencia según los pasajes sean narrativos o dialogados. En todo caso, hay que tener en cuenta que, dado el tipo de obra, casi todo el texto es dialogado. Véanse ejemplos en los dos tipos de discurso:

(72) Quando el rey vido que lo fiziera tan aína, cuidó que era sabio et agudo, et mandól' dar algo et buenos paños. Et él dio a bever la melezina a la dueña, et luego, commo la bevió, fueron los sus estentinos despedaçados et murió. (p. 192)

(73) Dixo el león: - Non creas que por acusarte los mis vasallos te faga yo ál salvo toda honra et bien, más que tú non querrás: et yo te anpararé dello[s] por mescla que sea. (p. 308)

Por otro lado, una constante, que, según afirma Company (2009a), se acentúa en el XV y XVI es que esta construcción se da en fragmentos en estilo directo y tras verbos de entendimiento y lengua. Es cierto que es una fórmula frecuente en estos contextos pero también tras otro tipo de verbos:

(74) Desí temíme que non podría sofrir la su vida et que me tornaría a la costunbre en que fuera criado. Et non fue seguro que, si me dexase del mundo et tomase religión, que lo non pudiese conplir, et dexaría algunas cosas que tenía començadas de que avría provecho. (p. 113)

(75) Et estonçe demandó el religioso un açadón, et tráxole al huésped, et yo estando en otra cueva ajena oyendo lo que dezían. Et avía en la mi cueva mill maravedís, et yo non sabiendo quien los posiera aí, enpero yo meneávalos et alegrávame] con ellos quando quier que me venía emientes. Así qu' el huésped cavó la cueva fasta que llegó a ellos, et sacólos. (p. 213) (p. 90)

En fin, en la época que estamos analizando, y en concreto en el Calila, esta construcción es relativamente frecuente en muy diferentes contextos; después, en el siglo XV, el tipo de texto va a ser determinante, pues va a pervivir en textos jurídicos o en el lenguaje proverbial, mientras que es difícil encontrarla en textos de otras tradiciones discursivas. Por otra parte, afirma Company (2009a: 776) que la construcción artículo + posesivo se pierde antes con el posesivo $s u(s)$, que es más polisémico y, a partir de ahí, se empuja a la desaparición de las otras personas. Esto no se ve aún en el texto analizado, pues los usos con $s u(s)$ son, precisamente, los más abundantes. Dice esta autora que, como el posesivo va convirtiéndose en determinante, los dos clíticos quedan imposibilitados de concurrir en un mismo sintagma nominal (2009a: 862) lo que acabará provocando la desaparición de esta construcción, desaparición que no es absoluta pues sigue perviviendo en algunas áreas hispanas, aunque, eso sí, en zonas restringidas y con valores pragmáticos muy determinados (Serradilla, 2003). 


\section{REFLEXIONES FINALES}

En las páginas precedentes he analizado la construcción artículo + posesivo + nombre frente a la construcción posesivo + nombre, que Mario Barra Jover (2009a y 2009b) apuntaba como una de las posibles estructuras que pueden catalogarse como variantes invisibles y que yo misma en un trabajo reciente (Serradilla, en prensa) ${ }^{21}$ ya comentaba como un caso más que posible de variante no motivada. En este trabajo he profundizado en el estudio de esta estructura y, tras analizar los distintos contextos en los que aparecen ambas construcciones y los distintos valores que pueden señalar, he llegado a la conclusión de que parece imposible encontrar una explicación de peso para poder afirmar que en el Calila el uso de una u otra construcción esté motivado y no sea una variante invisible usada de forma inconsciente por el autor/traductor.

Así, he estudiado los tipos de nombre que se incluyen en la construcción artículo + posesivo y he podido observar que no parece existir ningún tipo de limitación respecto a las subclases de nombres que pueden aparecer como poseídos. Asimismo, es de destacar la importante productividad léxica, en el sentido de que los nombres son muy variados y no parece haber ninguno que predomine frente a los demás. Además todos ellos (excepto elefante) se documentan en la época también con la estructura solo con posesivo.

Por otra parte, se ha observado cómo es más frecuente cuando se refiere a un solo poseedor; esto será mucho más evidente siglos después cuando se use para marcar la unicidad o el foco discursivo pero en esta época todavía encontramos casos en los que hay varios poseedores y, en este sentido, no parece que pueda ser considerado como un factor determinante a la hora de elegir una u otra estructura. Precisamente, en cuanto al poseedor, he podido observar cómo este puede ser tanto humano como no humano y no es, como ocurrirá siglos después, necesariamente un elemento de especial relevancia en el discurso.

He prestado también atención a la frecuencia de aparición de la estructura analizada dependiendo de si se encuentra en un sintagma nominal o en un sintagma preposicional y las diferencias no son tan significativas como para considerarlo un factor decisivo a la hora de optar por una u otra construcción. He analizado las funciones sintácticas de los sintagmas en los que aparece y se observa la misma variación que cuando se utiliza la construcción sin artículo. Dado, pues, que puede aparecer en SN que cumplen funciones muy diversas, parece evidente que la función no determina el uso de la construcción con o sin artículo.

He tenido en cuenta también la distancia con el referente y los datos no nos orientan hacia ninguna dirección, ya que lo habitual, independientemente de la construcción, es que la distancia con el referente sea corta. He atendido a la integridad semántica de esta construcción, que es incuestionable, igual que cuando no aparece el artículo, pero no se representa formalmente con ninguna marca determinada.

Me he centrado en el análisis de pasajes narrativos y dialogados, y tampoco en este caso se percibe una predilección por una u otra secuencia según el tipo de discurso en el que se insertan. También me he fijado en los verbos de las oraciones en las que se incluye

\footnotetext{
${ }^{21}$ Se trata de un trabajo presentado en el VIII Congreso Internacional de Historia de la Lengua, en el que ya apuntaban algunas de las propuestas discutidas en este estudio.
} 
esta construcción y hay que señalar que encontramos una gran variedad; he estudiado los valores pragmáticos, $\mathrm{y}$, como señalaba, no parece que aún se utilice esta estructura con la función de destacar el foco discursivo. En fin, he ido analizando uno por uno todos los parámetros que pudieran orientarnos hacia el porqué del uso de esta construcción y no he encontrado, como decía, ninguna prueba que nos oriente hacia un uso motivado.

Podría concluir, pues, en consonancia con las afirmaciones del profesor Barra, que en este momento y en esta obra en concreto estamos ante un autor, hablante, al fin y al cabo, como decía al principio de este trabajo, que utiliza de forma inconsciente, y sin que haya ninguna motivación sintáctica, pragmática ni semántica, la construcción con o sin artículo ante posesivo + nombre. Estaríamos, pues, hablando de que en el caso de la secuencia «artículo + posesivo + nombre» nos enfrentamos a una variante invisible, variante que, poco a poco, se irá haciendo visible frente a la construcción posesivo + nombre, que es la que ha perdurado en nuestra lengua.

Recojo, antes de terminar, unas últimas palabras de Barra Jover (2009b: 30):

Parece más que claro que toda lengua está permanentemente en estado de variación y que, en un momento dado, las variantes para tal o cual función pueden no ser controladas por los locutores. También parece claro que las variantes innovadoras, aunque hayan estado muy presentes en un periodo, no tienen por qué imponerse.

En este sentido es posible afirmar que en el caso de la estructura analizada el locutor (en este caso el traductor del Calila) no controla de forma consciente el uso de las variantes, igual que es de suponer que no lo harían muchos de sus coetáneos. También es de destacar que la variante innovadora no es la que acaba imponiéndose en nuestra lengua; así, los usos posteriores de esta construcción, ya como variante visible estigmatizada en la lengua general, tendrán un ámbito mucho más restringido a nivel geográfico y sociolingüístico, y mostrarán unos valores pragmáticamente muy marcados, que todavía en este texto no están presentes.

\section{CORPUS}

AnónImo: Calila e Dimna, ed. de Juan Manuel Cacho Blecua y Mª Jesús Lacarra, Madrid, Castalia, 1984.

Anónimo: Calila e Dimna, ed. de Antonio G. Solalinde [ed. en línea].

Real Academia Española: Banco de datos (CORDE) [en línea]. Corpus diacrónico del español. $<$ http://www.rae.es $>$ [Fecha de la consulta: junio-diciembre de 2009].

\section{REFERENCIAS BIBLIOGRÁFICAS}

Alvar, Carlos y Lucía, José Manuel (2002): Diccionario filológico de literatura medieval española: textos y transmisión, Madrid, Castalia.

BARRA JOVER, Mario (2009a): «Des variantes invisibles à la fragmentation des langues romanes», Recherches Linguistiques de Vincennes, vol.38, pp. 107-132.

BARRA Jover, Mario (2009b): «Las "variantes invisibles". El ejemplo de la evolución de las subordinadas y otros casos relacionados», La transformación del castellano medieval: sistema, formas de transmisión y entorno social, número monográfico de Cahiers D'Études Hispaniques Médiévales, $\mathrm{n}^{\circ}$ 32, pp. 17-32. 
Clavería Nadal, Gloria (1993): «La construcción artículo + posesivo en los siglos XIV y XV», Actas del I Congreso Internacional de Historia de la Lengua Española, Madrid, Arco-Libros, pp. 347-357.

COMPANY, Concepción (2006): «Persistencia referencial, accesibilidad y tópico. La semántica de la construcción artículo + posesivo + sustantivo en el español medieval», RFE, vol. LXXXVI, pp. 65-103.

COMPANY, Concepción (2009a): «Artículo + posesivo + sustantivo y estructuras afines», en C. Company (dir): Sintaxis histórica de la lengua española. Segunda parte: la frase nominal, vol 1, México, Universidad Nacional Autónoma de México y Fondo de Cultura Económica, pp. 759880.

COMPANY, Concepción (2009b): «La sintaxis histórica nominal en la obra de Rafael Lapesa: tradición e innovación» en José Jesús de Bustos y Rafael Cano (eds.), La obra de Lapesa desde la Filología actual, Madrid, Sociedad estatal de conmemoraciones culturales.

Gómez SeIBANe, Sara (en prensa): «De nuevo sobre artículo+posesivo+sustantivo. Textos vizcaínos de los siglos XV-XVIII», Nueva Revista de Filología Hispánica, 58/1.

KABATEK, Johannes (2008): Sintaxis histórica del español y cambio lingüístico: nuevas perspectivas desde las Tradiciones Discursivas, Frankfurt/Madrid, Vervuert-Iberoamericana.

Moral del Hoyo, $\mathrm{M}^{\mathrm{a}}$ Carmen (2006): «Hacia una tradición discursiva de las cartas de venta en el espacio vasco-románico de la Baja Edad Media», Oihenart, 21, pp. 357-376.

Palacios, Azucena (2004): «El valor discursivo en las construcciones de artículo indefinido + posesivo + nombre en el español de Centroamérica», Signo y Seña (Buenos Aires), vol. 13, pp. $185-214$.

PAто, Enrique (1999): «Sobre el artículo con posesivo en español medieval», UAM: ms.

PATO, Enrique (2002): «La estructura posesiva una mi amiga en el español de Guatemala», en Azucena Palacios y Ana Isabel Garcia Tesoro, El indigenismo americano III, Valencia, Universitat, Cuadernos de Filología, pp. 121, 154.

Picallo, M. Carme y Rigau, Gemma (1999): «El posesivo y las relaciones posesivas», en Bosque, Ignacio y Violeta Demonte (eds.), Gramática descriptiva de la lengua española, Madrid, Espasa Calpe, vol. 1, pp. 973-1023.

Serradilla Castaño, Ana (2003): «¿Existe la originalidad en sintaxis? El caso de la «desaparición» de la construcción «artículo + posesivo» en español», Pandora. Revista interdisciplinar de la Universidad de París VIII/3, pp. 257-272.

SERRAdilla Castaño, Ana (2007): «Sobre la evolución del artículo + posesivo en el español peninsular: causas de su pervivencia y comparación con la situación del español americano», $A c$ tas del XXIV Congres International de Linguistique et Philologie Romanes, tomo II, Tubingen, Max Niemeyer, pp. 319-330.

SERRADIlla Castaño, Ana (en prensa): «¿Es una «variante invisible» la alternancia «artículo + posesivo + nombre»- «posesivo+nombre» en la prosa medieval? El caso del Calila», Actas del VIII Congreso Internacional de Historia de la lengua. 
